\title{
International Primary Care Respiratory Group (IPCRG) Guidelines: Integrating diagnostic guidelines for managing chronic respiratory diseases in primary care
}

\author{
Ron J. Halbert ${ }^{a, *}$, Sharon Isonaka ${ }^{b}$
}

\author{
a Cerner Health Insights, and UCLA School of Public Health, 9100 Wilshire Blvd., \\ Suite 655E, Beverly Hills, CA 90212, USA \\ b i3 Magnifi, 1601 Cloverfield Boulevard, 2nd Floor, South Tower, Santa Monica, CA 90404, USA
}

KEYWORDS

Guideline;

Respiratory diseases;

Primary care;

General practice;

Diagnosis

Integrated;

Diagnostic framework

\begin{abstract}
Summary This is the first of the IPCRC Graetiliedopers. The IPCRG took on the task of producing an integrated sl id - tne for the management of chronic respiratory diseases in primery cale dris included spmetorimal work aimed at developing questionn : if sultable for improving na diagncsis and recognition of respiratory discases in the primaly farle seiting. This paper provides the background evidence and rationate ro r the int es ated diagnostic section of the IPCRG Guideline. It focusses A dentifying the unique challenges in respiratory disease diagnosis in primary care, the use of epidemiology to build a co-ordinated diagnostic framework, and the development of tools to support guideline implementation.

(c) 2005 General Practice Airways Group. Published by Elsevier Ltd. All rights reserved.
\end{abstract}

\section{Introduction}

The International Primary Care Respiratory Group (IPCRG) took on the task of producing an integrated guideline for chronic respiratory diseases, to be drawn from existing guidelines produced by Allergic Rhinitis and its Impact on Asthma (ARIA) [1], the Global Initiative for Asthma (GINA) [2], and the Global Initiative for Chronic Obstructive Lung Disease (GOLD) [3]. Since each of these existing

\footnotetext{
* Corresponding author. Tel.: +1 310598 4462; fax: +18169361862.

E-mail address: rhalbert@cerner.com (R.J. Halbert).
}

guidelines addresses a single disease, one key challenge was to coordinate diagnosis across all three disease states. Diagnosing chronic respiratory disease in the primary care setting can be difficult in itself, and the task of integrating existing guidelines for three disease processes poses special challenges.

Another important task was to adapt guidelines for implementation in the primary care setting. Implementing guidelines can be difficult, and general practitioners (GPs) can often benefit from tools and simplified algorithms to enable them to adapt and implement guidelines while meeting the demands and limitations of busy primary care practice settings. 
This report provides the evidence and rationale for the integrated diagnostic section of the new guideline [4]. We will focus on: (1) identifying unique challenges in respiratory diagnosis; (2) using epidemiology to build a coordinated diagnostic framework, and; (3) developing tools to support guideline implementation.

\section{Unique Challenges of Respiratory Diagnosis}

\section{Overlap between allergic rhinitis and asthma}

There are important epidemiological and pathophysiological links between allergic rhinitis and asthma, suggesting a strong relationship between the two [1]. The current view is that both upper and lower airways are affected by a common inflammatory process. For this reason, the two conditions should be considered together. Other upper respiratory conditions may occur in conjunction with allergic rhinitis, thus complicating diagnosis. These include sinusitis, conjunctivitis, nasal polyposis, and otitis media.

\section{Underdiagnosis of asthma}

Underdiasnosis of alst.nna may be attributed $t$ d a varietw 6 ractors, includirio lich of patient awareness of the disease, reluctance to seek health care in response to respiratory symptoms, and underdiagnosis by GPs [5]. In a general practice setting, asthma diagnosis can be difficult because patient symptoms are intermittent and often nonspecific and because there is a spectrum of clinical presentations [2]. By definition, patients with asthma often demonstrate wide fluctuations in symptoms, and variations in lung function and response to medication. As a result, patient presentation may vary between overt signs and symptoms of the disease or none at all. The boundaries for distinguishing asthmatic patients from those without asthma are not absolute [6], and there is no single test or pathognomic feature which is definitive for the presence or absence of asthma [7]. Asthma is typically diagnosed in the clinical setting based on a combination of history, physical examination, and physiologic testing (i.e., lung function), often over a period of time. Patients with asthma are often misdiagnosed as suffering from recurrent upper or lower respiratory tract infections; therefore, a thorough perusal of the past medical record, together with detailed history-taking, may often provide additional evidence to support a diagnosis of asthma [8-10].

\section{Asthma in young children}

The diagnosis of asthma in infants is difficult. The largest proportion of children under 5 years of age with wheezing are transient wheezers who do not have asthma. In many cases, it is not possible to discriminate between transient wheezers and asthma at an early age, although a positive family history of atopic disease, presence of eczema in the child, and a good response to bronchodilators and/or corticosteriods are more suggestive for asthma. The differential diagnosis of asthma in young children is considerable and includes bronchiolitis, recurrent ENT infections, gastro-oesophageal reflux, cystic fibrosis, congenital anomalies of the airways/lungs, and congenital heart defects. Young children whose primary symptom is recurrent or persistent cough, or who wheeze with respiratory infections, are often misdiagnosed as having bronchitis or pneumonia and thus ineffectively treated with antibiotics or cougti supp essants [2]. Diagnosis is further cornoplicated by the difficulty of nerforming Wris function testing in young childreri.

\section{Oicupational asthma}

Workers exposed to inhalant chemicals or allergens in the workplace can develop asthma and may be misdiagnosed as having chronic bronchitis or chronic obstructive pulmonary disease (COPD). Early recognition, strict avoidance of further exposure, and early treatment are essential [2]. Diagnosis of these patients may require help from a specialist [11].

\section{Underdiagnosis of COPD}

Underdiagnosis of COPD is common as this disease is often not recognised and diagnosed until it is moderately advanced [3]. Since COPD develops slowly, patients with early disease may have few symptoms; therefore, they may not seek medical help, and their doctor may not recognize that they have damaged lungs. Many patients adapt to their symptoms, gradually decreasing their activity level over time, without seeking medical help [12]. Some symptoms associated with COPD, such as cough and sputum production, are nonspecific. It is difficult to measure how often this disease is missed, but the figure of $50 \%$ undiagnosed cases is commonly cited [13]. Many of these undiagnosed cases are at an 
early stage of disease when efforts to halt disease progression would be most effective.

\section{Underuse of spirometry in primary care}

One of the barriers to the diagnosis of COPD is the difficulty with which spirometry is performed in the general practice setting. Limitations in equipment and time contribute to the fact that primary care physicians rarely use spirometry to detect COPD, as recommended in the guidelines [14-19].

\section{Overlap between COPD and asthma}

Overlap between the clinical pictures of asthma and COPD commonly leads to problems in distinguishing these two conditions. Patients with COPD are often incorrectly labelled as having asthma $[20,21]$. Accurately distinguishing between asthma and COPD is recognised as a major diagnostic challenge in the clinical setting. Shortness of breath is a common feature of both conditions, and it can be difficult to distinguish asthma and COPD in some patients [22-25]. In the case of patients with combined asthma and COPD, the degree of reversibility in airflow obstruction alone may be insufficient to establish a clear diagnosis. In older adults, this problem is particularly acute. The National Asthma Educition and Prevention Program in the JsA.issted a report highlighting special conis icteracions for managing: asthma ir the E(c) le ly [21). The report no ed liat some eldery patients displar cira acteristics of both asthma (i.e., some reversibility of airway obstruction) and COPD (i.e., some degree of nonreversible obstruction), thus creating diagnostic confusion. The report also addressed the need to differentiate asthma from other conditions seen with increased frequency in older populations, such as interstitial lung disease, bronchiectasis, cardiac disease (such as angina and congestive heart failure), upper airflow obstruction, pulmonary embolism, bronchogenic carcinoma, aspiration, and gastroesophageal reflux.

\section{Differing guideline approaches}

In addition to disease-specific challenges, the existing ARIA [1], GINA [2], and GOLD [3] guidelines employ different approaches to diagnosis. The ARIA guideline indicates that the diagnosis of allergic rhinitis should be based on the history of allergic symptoms and diagnostic testing directed towards the detection of IgE or IgE-mediated allergic reactions [1]. The GINA guidelines emphasize the role of the medical history and physical examination in the diagnosis of asthma, emphasizing the classic presentation of episodic dyspnoea or chest tightness and findings of expiratory wheezes [2]. Pulmonary function and additional studies are used primarily to confirm the diagnosis. GOLD, on the other hand, begins with symptoms (cough and sputum) and risk exposure (primarily cigarette smoking), but presents spirometry as the primary approach for identifying airway obstruction, providing standardized protocols for interpreting lung function tests [3]. The differences between these approaches exacerbates the diagnostic problems faced by the primary care health professional, who must evaluate patients with consideration of all relevant diseases.

\section{Developing An Epidemiologic Framework}

The epidemiology of chronic respiratory diseases lends support for an approach to diagnosis that reflects different clinical presentations based on age demographics.

Allergic rhinitis is unlikely in children below 3-4 years of age [27], and allerger specitic serum IgE tests and allergy skiri Gesing are less reliable in childran incent the age of three [28]. The Petidence of rhinitis in older children varies widely, from $6.9 \%$ (t) $14.9 \%$ in the $6-7$ year-old are givu and rom $1.4 \%$ to $39.7 \%$ in the $13-14$ year-old group, and allergic rhinitis is significantly correlated with asthma in this group [2]. This relationship between allergic rhinitis and asthma continues into adulthood.

Among children, asthma prevalence has been measured at between $0-30 \%$ in various populations [2]. Data on asthma prevalence in adults are more controversial, and large variations in asthma prevalence have also been found for adults across different populations. Asthma epidemiology clearly differs for population sub-groups of children, adults, and the elderly, due to changes in lung function, exposure to risk factors, and other factors over the life span. Differential diagnosis considerations also vary widely for these sub-groups, complicating the diagnostic approach. For example, in preschool children, the younger the child the greater the likelihood that something other than asthma explains recurrent wheezing [2]. The age threshold at which a child can actively participate in lung function testing serves as an important demarcator for diagnostic purposes. GINA guidelines recognize the elderly, paediatric, and occupational populations as posing specific challenges with respect to the diagnosis of asthma [2]. 


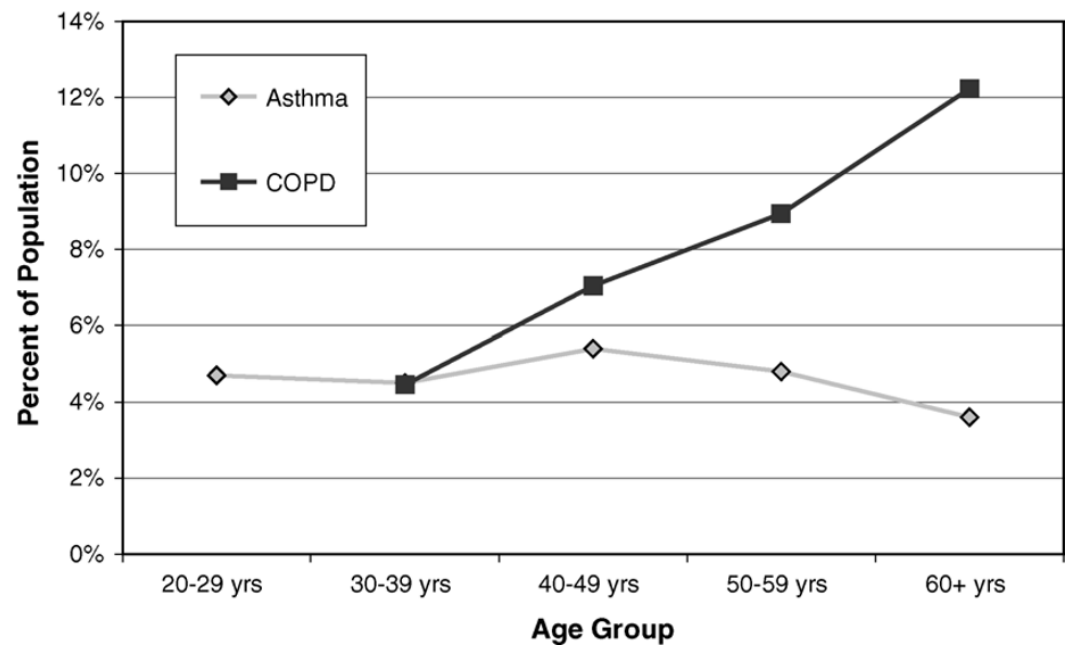

Figure 1 Prevalence of Patient-Reported Asthma and COPD [reproduced from 46].

Nationally representative USA surveys illustrate age-specific prevalence trends in asthma relative to COPD in adults. Data from the National Health Interview Survey show that the prevalence of self-reported asthma peaks in the 12-17 year old age group at $14.2 \%$ [29], drops to $9.2 \%$ among $18-44$ year olds, and continues to decrease gradually with age [30]. At the same time, the prevalence of emphysema and chronic bronchitis begins a st ady increase, starting from rates of $0.3 \%$ ard $3.5 \%$ respectively in 18 $44 \%$ alar cids. Data from the Third Nationat Health aric Nutrition Fxamination.
Survey illustrate the rise in patient-reported COPD with age (Figure 1) [31,32]. Among adults aged 30-39 years, COPD is no more common than asthma; COPD prevalence then rises steadily with age until, over the age of 60, COPD is three times more common than asthma. IVinen airway obstruction is considere (1)incer endent of diagnostic label, the Iis W W il age is even more pronounced [3]2]

Taken togethefths evidence suggests discrete diagricstic grups, each of which require a tailored diagnostic approach (Table 1).

Table 1 Chronic Respiratory Diseases: Principal Epidemiologic and Diagnostic Issues

\begin{tabular}{|c|c|c|}
\hline Age Group & Primary Epidemiologic Issues & Primary Diagnostic Issues \\
\hline Young children (under age 5-6) & $\begin{array}{l}\text { Asthma not the most common cause of } \\
\text { chronic respiratory symptoms } \\
\text { Allergic rhinitis is uncommon under } \\
\text { age } 4\end{array}$ & $\begin{array}{l}\text { Exclude competing causes of } \\
\text { chronic respiratory symptoms } \\
\text { Lung function testing not available }\end{array}$ \\
\hline \multirow[t]{2}{*}{ Older children (age 6 and older) } & $\begin{array}{l}\text { Asthma and allergic rhinitis are the } \\
\text { most common causes of chronic } \\
\text { respiratory symptoms }\end{array}$ & Document reversible obstruction \\
\hline & & Consider coexisting atopic disease \\
\hline \multirow[t]{3}{*}{ Younger adults (up to age $40-45$ ) } & $\begin{array}{l}\text { Asthma and allergic rhinitis are the } \\
\text { most common causes of chronic } \\
\text { respiratory symptoms }\end{array}$ & Document reversible obstruction \\
\hline & $\begin{array}{l}\text { Occupational exposures may be } \\
\text { important }\end{array}$ & Consider coexisting atopic disease \\
\hline & & $\begin{array}{l}\text { Identify occupational contribution } \\
\text { (if any) }\end{array}$ \\
\hline \multirow[t]{3}{*}{ Older adults (age 40 and older) } & $\begin{array}{l}\text { COPD is more common than asthma, } \\
\text { but may be asymptomatic }\end{array}$ & COPD case-finding \\
\hline & $\begin{array}{l}\text { Characteristics of COPD and asthma } \\
\text { may overlap }\end{array}$ & Differentiate asthma from COPD \\
\hline & & $\begin{array}{l}\text { Identify occupational contribution } \\
\text { (if any) }\end{array}$ \\
\hline
\end{tabular}




\section{Developing Tools to Facilitate Diagnosis in Primary Care}

Guidelines are difficult to implement, and dissemination alone is insufficient to guarantee uptake $[33,34]$. Lowering barriers to acceptance can help. Approaches include summary algorithms that guide practitioners through the key points of a guideline, and support tools to help simplify key decisions. Although these types of tools are more often designed to aid treatment decision-making, the same approach may be applied to diagnosis.

\section{Diagnostic algorithm}

For the IPCRG guidelines, a diagnostic algorithm was based on the age groups and primary diagnostic issues described above. As with all guidelines, this algorithm represents an oversimplification of the complex diagnostic issues at hand. Nevertheless, it provides an integrated approach to diagnosis, and creates a logical flow of patients through a busy practice.

\section{Case-finding Tools}

Since respiratory symptoms are among the most common presenting complaints in prima yedare, it is impractical to invesiligcte fulvevery patient: with sympiom: Vtr is inore helpful to focus on patients micst likely to berefit from a full diagnostic evaluation. Screening and case finding are two approaches commonly used to accomplish this. Screening typically involves investigating large numbers of people, either in a widespread population-based effort or in a more focused fashion within a specific target population. In the primary care setting, screening often translates to investigation of largely asymptomatic patients. This can be costly and time-consuming, often with a low return on effort. Case-finding is a more targeted approach, relying on identifying patients with a higher probability of having the disease in question. In primary care diagnosis of respiratory disease, case-finding with the use of symptoms and risk factors is a more realistic approach. We focused on a case-finding approach that begins with a patient's presentation of symptoms and signs suggestive of respiratory disease.

Although lists of symptoms and risk factors are frequently listed as diagnostic aids, specific question items are infrequently tested for their ability to discriminate persons with and without disease. We searched the literature for questionnaire instruments demonstrated to be valid for diagnosis. In cases where no validated instrument was available, we searched for individual question items, or created and tested new items for this purpose. In all cases, we sought instruments that could be easily administered in a primary care setting with a minimum administrative burden. Since many of the instruments described in the literature were developed for epidemiological or other scientific investigation, they can be quite lengthy, and yet there was little evidence to suggest that a longer instrument improved diagnostic ability. In order to facilitate easy use, we aimed for relatively short question lists, with a target of 5-10 items.

The case-finding tools adopted for the integrated IPCRG guidelines are described below.

- The Allergic Rhinitis Questionnaire was developed by a working group of specialists based primarily upon expert opinion [35].

- The Childhood Asthma Questionnaire was developed based on literature review, a Delphi approach, and a synthesis of question items previously tested and shown to be predictive [36-39].

- The Adult Asthma Question Zaire Q/as Jeveloped from a syinthesi. A usstion items previously testec and shown to be predictive [40-43].

The COPD Question naire was developed based on literolure review, retrospective data analyses, and a Delphi approach. Using prospective methodology, this set of questions has been validated and shown to support diagnosis in a primary care setting [44].

- The Differential Diagnosis Questionnaire was developed along similar lines to the COPD Questionnaire. Using a similar validation process, this tool has been demonstrated to support diagnosis in a primary care setting [45].

Once a patient is placed in a likely diagnostic category using the appropriate questionnaire, more specific guidance can be derived from the summary documents provided by IPCRG, or by referring to the more detailed evidence-based guidelines from ARIA [1], GINA [2], and GOLD [3]. These provide guidance on interpretation of history, physical examination and response to treatment over time, as well as the results of diagnostic tests when available.

\section{Conclusions}

Diagnosis of the patient with chronic respiratory disease in the primary care setting requires an integrated approach based upon patients' symptomatic presentation. The recommended 
IPCRG approach to diagnosis of respiratory diseases in the primary care setting utilizes a combination of triage by age, initial diagnostic assessment using patient self-reported information (questionnaires and data collection forms), and different levels of confirming evidence based upon available infrastructure.

- For patients with respiratory symptoms, a self-administered questionnaire or data collection form is used based upon age and risk factors.

- This can be easily and efficiently implemented in the practice setting and will provide initial diagnostic assessment that can then be confirmed by the physician.

- Under minimal infrastructure conditions, the initial assessment is confirmed based on findings from history, physical examination, and response to treatment over time.

- Under optimal infrastructure conditions, more definitive testing using spirometry with reversibility testing, peak flow measurement, and allergic testing may be added as needed to provide additional confirmation.

- Patients for whom initial diagnostic assessments cannot be confirmed in the context of available infrastructure should be strongly considered for specialist evaluation.

\section{We believe that this crovides a unifying appred ch to the diag osi: of ciespiratory disec ies nkich integrates major guideline recommendations and which can be implemented in any primary care setting.}

\section{Acknowledgments}

Although this paper was produced without external funding, much of the work described was supported by grants from Boehringer Ingelheim $\mathrm{GmbH}$. The authors would like to thank Drs. Claus Justus and Dmitry Nonikov for their support.

\section{References}

[1] Bousquet J, Van Cauwenberge P, Khaltaev N, Aria Workshop Group; World Health Organization. Allergic rhinitis and its impact on asthma. J Allergy Clin Immunol 2001;108(5 Suppl):S147-334. Other materials available at URL: www.whiar.com/ (accessed 12 May, 2005).

[2] Global Strategy for Asthma Management and Prevention. NIH Publication No 02-3659 Issued January, 1995 (updated 2002). Available at URL: www.ginasthma.org (accessed 12 May, 2005).
[3] Global Initiative for Chronic Obstructive Lung Disease. Global Strategy for the Diagnosis, Management, and Prevention of Chronic Obstructive Pulmonary Disease. National Institutes of Health, National Heart, Lung, and Blood Institute; April 2001 (Updated 2004). Available at URL: http: / / www.goldcopd.com.

[4] Levy ML, Fletcher M, Price DB, Hausen T, Halbert RJ, Yawn BP. International Primary Care Respiratory Group (IPCRG) Guidelines: Diagnosis of Respiratory Diseases in Primary Care. Prim Care Resp J 2005;15(1):20-34.

[5] van den Boom G, Rutten-van Molken MP, Tirimanna PR, van Schayck $C P$, Folgering $H$, van Weel $C$. Association between health-related quality of life and consultation for respiratory symptoms: results from the DIMCA programme. Eur Respir J 1998;11:67-72.

[6] Pride NB. Asthma. Definition and clinical spectrum. Br Med Bull 1992;48:1-9.

[7] Kemp T, Pearce N, Crane J, Beasley R. Problems of measuring asthma prevalence. Respirology 1996;1:183-8.

[8] Levy M, Bell L. General practice audit of asthma in childhood. Br Med J (Clin Res Ed) 1984;289:1115-6.

[9] Levy M. Delay in diagnosing asthma-is the nature of general practice to blame? J R Coll Gen Pract 1986;36:52-3.

[10] Levy M, Hilton S. Asthma in Practice. Fourth Ed. London: Royal College of General Practitioners; 1999.

[11] American Thoracic Society. Guidelines for assessing and managing asthma risk at work, school, and recreation. Am J Respir Crit Care Med 2004;169:873-81.

[12] Rennard S, Decramer M, Calverley PM, et al Impact of COPD in North America and Europe i 12000 , subject; perspective of Confronting COR, /hornatio al survey. Eur Respir J 2007;20;99-80

[í3. Na iona Lung Health Education Program. Strategies in preserving lurig heal $\mathrm{h}$ and preventing COPD and associated dises $S$ Ches: $1208,113(2$ Suppl):123S-63S.

[14] =rgu son GT, Enright PL, Buist AS, Higgins MW. Office spirometry for lung health assessment in adults: A consensus statement from the National Lung Health Education Program. Chest 2000;117:1146-61.

[15] Hansen JG, Schmidt H. Obstructive ventilatory impairment: An investigation in general practice. Scand J Prim Health Care 1991;9:227-31.

[16] den Otter JJ, van Dijk B, van Schayck CP, Molema J, van Weel $C$. How to avoid underdiagnosed asthma/chronic obstructive pulmonary disease? J Asthma 1998;35:381-7.

[17] Tirimanna PR, van Schayck CP, den Otter JJ, et al. Prevalence of asthma and COPD in general practice in 1992: has it changed since 1977? Br J Gen Pract 1996;46:277-81.

[18] Kesten S, Chapman KR. Physician perceptions and management of COPD. Chest 1993;104:254-8.

[19] Mapel DW, Picchi MA, Hurley JS, et al. Utilization in COPD: patient characteristics and diagnostic evaluation. Chest 2000;117(5 Suppl 2):346S-53S.

[20] Mousley K, Rudolf M, Pearson M. General practitioner prescribing habits in asthma/COPD [abstract]. Thorax 1996;51 (suppl 3):A26 P1.

[21] Marklund B, Tunsater A, Bengtsson C. How often is the diagnosis bronchial asthma correct? Fam Pract 1999;16:112-6.

[22] Littlejohns P, Ebrahim S, Anderson R. Prevalence and diagnosis of chronic respiratory symptoms in adults. BMJ 1989;298:1556-60.

[23] Barbee RA, Dodge R, Lebowitz ML, Burrows B. The epidemiology of asthma. Chest 1985;87(1 Suppl):21S-5S.

[24] Snider GL. Distinguishing among asthma, chronic bronchitis, and emphysema. Chest 1985;87(1 Suppl):35S-9S. 
[25] van Schayck CP. Diagnosis of asthma and chronic obstructive pulmonary disease in general practice. $\mathrm{Br} J$ Gen Pract 1996;46:193-7.

[26] National Asthma Education and Prevention Program Working Group on Asthma in the Elderly. Considerations for Diagnosing and Managing Asthma in the Elderly. National Institutes of Health Publication No. 02-3659. Bethesda, MD, 1996. Available at URL: http://www.nhlbi.nih.gov/ health/prof/lung/asthma/as_elder.pdf.

[27] Kulig M, Bergmann R, Klettke U, Wahn V, Tacke U, Wahn $U$. Natural course of sensitization to food and inhalant allergens during the first 6 years of life. J Allergy Clin Immunol 1999;103:1173-9.

[28] Bush A. Chronic cough and/or wheezing in infants and children less than 5 years old: diagnostic approaches. In: Naspitz CK, Tinkelman DG, Szefler SJ, Warner JO, editors. Textbook of Pediatric Asthma: An International Perspective. London: Martin Dunitz; 2001.

[29] Blackwell DL, Tonthat L. Summary health statistics for U.S. Children: National Health Interview Survey, 1998. Vital Health Stat 2002; 10(208):7. Available at URL: http://www.cdc.gov/nchs/data/series/sr_10/sr10 208.pdf.

[30] Pleis JR, Coles R. Summary health statistics for U.S. Adults: National Health Interview Survey, 1998. Vital Health Stat 2003; 10(209):19. Available at URL: http://www.cdc.gov/nchs/data/series/sr_10/sr10 209.pdf.

[31] Arif AA, Delclos GL, Lee ES, Tortolero SR, Whitehead LW. Prevalence and risk factors of asthma and wheezing among US adults: an analysis of the NHANES III data. Eur Respir J 2003;21:827-33.

[32] Celli BR, Halbert RJ, Isonaka S, Schau B. Population impart of different definitions of airway obstruction. Eur Respi 2003;22:268-73.

[33] Pearson MG. How can the int tement tien or guidelines be improve a? (he 2 20)(1); 7, 2 Suppl):38S-41S.

[34] Oxman AD, Thenson MA, Davis DA tid) ne: $B$ No magic bullets: a systematic review of $10<$ trials of interventions to improve professional practice. Can Med Assoc J 1995;153(10):1423-31.

[35] Adapted from Allergic Rhinitis and its Impact on Asthma (ARIA). Management of Allergic Rhinitis Symptoms in the
Pharmacy: ARIA in the Pharmacy. 2003. Available from http://www.whiar.org/.

[36] Frank TL, Frank PI, MCNamee R. Assessment of a simple scoring system applied to a screening questionnaire of asthma in children aged 5-15 years. Eur Respir J 1999;14:1190-7.

[37] Jenkins MA, Clarke JR, Carlin JB, et al. Validation of questionnaire and bronchial hyperresponsiveness against respiratory physician assessment in the diagnosis of asthma. Int J Epidemiol 1996;25:609-16.

[38] Shaw RA, Crane J, Pearce N, et al. Comparison of a video questionnaire with the IUATLD written questionnaire for measuring asthma prevalence. Clin Exp Allergy 1992;22:561-8.

[39] Wolf RL, Berry CA, O'Connor T, Coover L. Validation of the Brief Pediatric Asthma Screen. Chest 1999;116:224S-8S.

[40] Abramson MJ, Hensley MJ, Saunders NA, Wlodarczyk JH. Evaluation of a new asthma questionnaire. J Asthma 1991;28:129-39.

[41] Burney PG, Laitinen LA, Perdrizet S, et al. Validity and repeatability of the IUATLD (1984) Bronchial Symptoms Questionnaire: an international comparison. Eur Respir J 1989;2:940-5.

[42] Ravault C, Kauffmann F. Validity of the IUATLD (1986) questionnaire in the EGEA study. International Union Against Tuberculosis and Lung Disease. Epidemiological study on the Genetics and Environment of Asthma, bronchial hyperresponsiveness and atopy. Int J Tuberc Lung Dis 2001;5:191-6.

[43] Sistek D, Tschopp JM, Schindler C, et at. Cihil Clliagnosis of current asthma: predictive Glue $0^{t}$ lespiratoly symptoms in the SAPA LDIA st C $\%$. S. il:s s sudy on Air Pollution and Lung Disea. es in Acults. Eur Respir J 2001;17:214-9.

1417] Price DB, Tinkelm $n 2 C$, Halbert RJ, et al. Symptom-based questionl aire for idaritlíying COPD in smokers. Respiration [D k li-hed electronically December 5, 2005].

[45] Tinkelman DG, Price DB, Nordyke RJ, et al. Symptombased questionnaire for differentiating COPD and asthma. Respiration [published electronically December 5, 2005].

[46] van Schayck CP, Levy ML, Chen JC, Isonaka S, Halbert RJ. Coordinated diagnostic approach for adult obstructive lung disease in primary care. Prim Care Respir J 2004;13: 218-21.

Available online at www.sciencedirect.com

science@direct.

Available online at http://www.thepcrj.com 